\title{
Reconditioning of Worn Process equipment Using Composite Materials
}

\author{
Vyacheslav Aleksandrovich Ivanov \\ Russian State University of Tourism and Service, Russia
}

\section{ABSTRACT}

This article is devoted to reconditioning of working surfaces of equipment exposed to abrasive, corrosive, and cavitation wears. Importance of implementation of rational reconditioning methods at enterprises is discussed. The reasons and properties of wear types are listed, peculiar attention is paid to cavitation wear and its consequences. Classification of faults and reconditioning methods of worn working surfaces are described, it is proposed to use composite materials on polymer basis with various fillers; composite materials with ceramic fillers are more preferred as the most wear resistant ones and providing restoration of numerous wears of process equipment and pipelines. The article presents physicomechanical properties of compounds with ceramic fillers. In order to solve the formulated problems, practical proposals are given with regard to application of composite materials available at Russian market. The most suitable materials are determined on the basis of quality/price ratio. Examples of performed activities are given, economic efficiency of reconditioning using
\end{abstract}

composite materials is highlighted. Major advantages of the proposed technology are described.

Key words: Reconditioning technology, wear, corrosion, composite materials, ceramic fillers, wear resistance.

\section{INTRODUCTION}

Equipment and life support systems of various industries and housing sector during operation are exposed to various kinds of wear under dynamic impact of water and coolants, shocks of abrasive particles (sand and others), corrosive and cavitation processes. This leads to occurrence of various faults in the form of cavities, cracks, thinning of walls and, sometimes, their destructions with depressurization and leakages from life support systems (Figure 1).

During wear walls are thinning, openings vary, which leads to pressure loss in the equipment (Figure 2).

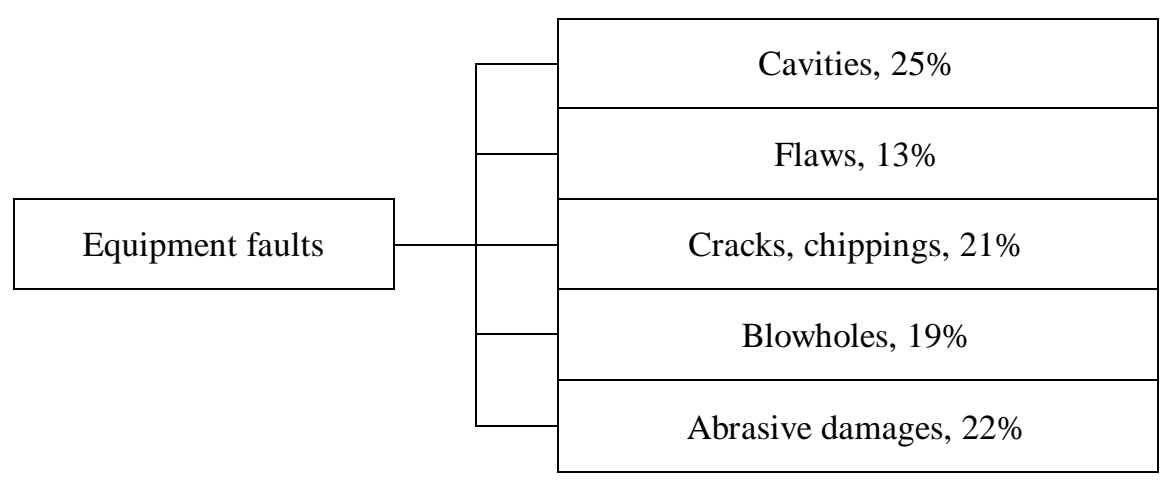

Figure 1: Equipment faults
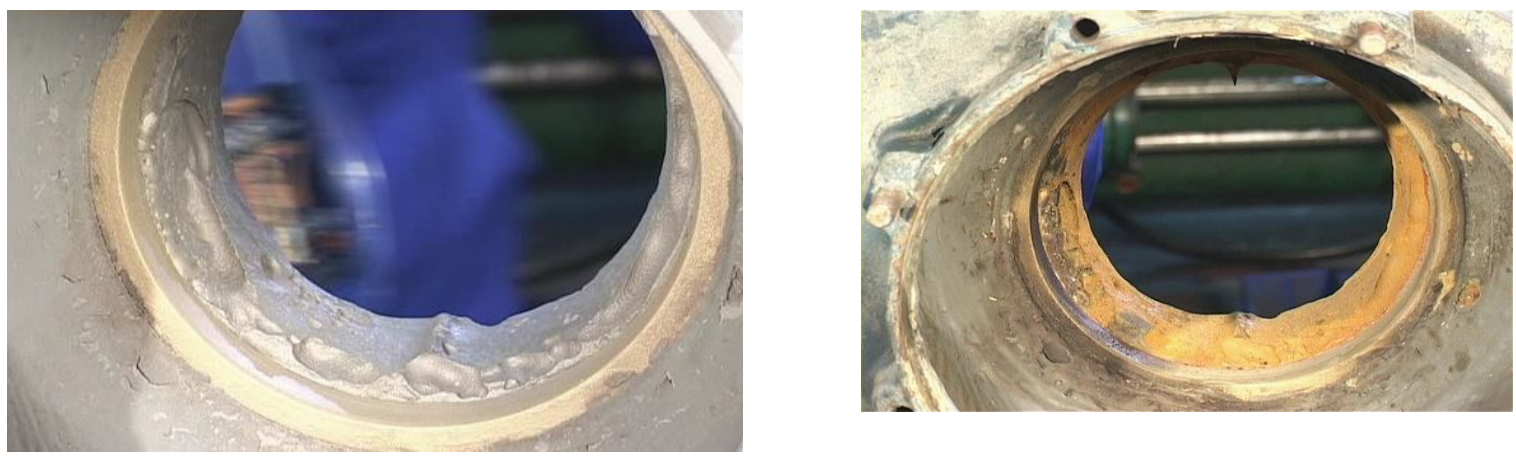

Figure 2: Wear of pump volute internal surface 
As a consequence of various wears: abrasive, corrosive, and cavitation, the properties of equipment vary, which affects negatively its production rate and leads to failures. In order to eliminate the results of wear, its types were considered, and appropriate composite materials and technologies were selected, which provided reconditioning of mining equipment.

Experiments have demonstrated that there are several types of abrasive wear, all of them are mechanical, that is, comprised of material segregation from surface as a consequence of mechanical impacts. Abrasive wear itself is mechanical wear of materials mainly during cutting or scratching action of solid particles in free or fixed state.

Hydroabrasive wear is the result of action of solid particles suspended in liquid and moving with regard to wearing body. Impact and abrasive wear takes place upon dynamic contact of interacting surfaces provided that there are particles between them with higher hardness in comparison with indenter and coating.

Surface destruction takes place under the action of abrasive materials. Abrasive material is natural or anthropogenic mineral, the particles (grains) of which are characterized by sufficient hardness and cutting (scratching) ability.

Polymer composite materials of certain composition used as coatings can withstand abrasive destruction because due to selection of fillers, it is possible to obtain superior mechanic properties in comparison with abrasive medium. Therefore, their application against abrasive wear attracts definite interest [1].

Equipment and devices made of metal materials and alloys upon operation in natural or anthropogenic media are also exposed to corrosion, which results in spontaneous destruction of metals as a consequence of their interaction with ambient environment. Due to the corrosion, the properties of metal vary, quite often its functional properties deteriorate. This is fully applied to equipment of water and heat supply systems the main units and elements of which are made of iron carbon alloys. Anticorrosion protection is comprised of processes or tools applied for decrease or elimination of metal corrosion. Repair composite materials on polymer base are exactly such tool since they are characterized by distinct anticorrosion properties and resistance against liquid and aggressive media [2].

Peculiar attention should be paid to destruction of metal surface under the impact of cavitation. Cavitation is a phenomenon in which rapid changes of pressure in a liquid lead to the formation of small vapor-filled cavities in places where the pressure is relatively low. This phenomenon can be explained as follows. In a rapidly moving flow, upon its narrowing and existence of obstacles, its pressure can drop to the point of vapor formation at given temperature. Herewith, depending on liquid resistance against tensions, rupture can occur, violation of flow integrity. The formed cavity is filled with vapor and gases extracted from liquid. Air entrapped into the flow promotes occurrence of cavitation. The formed vapor-gas bubbles with the sizes of tenth of millimeter moving with the flow reach the areas of high pressure. Vapor is condensed, gases are dissolved, and liquid particles are directed at high acceleration into the formed voids; the flow integrity is recovered accompanied by shock.

It has been shown by filming that a cavitation bubble can increase to $6 \mathrm{~mm}$ in diameter in $0.002 \mathrm{~s}$ and be completely destroyed in $0.001 \mathrm{~s}$. According to Karelin, under certain types of cavitation in the area of $1 \mathrm{~cm}^{2}$, during $1 \mathrm{~s}$ more than 30 million of cavitation bubbles can be formed and destroyed [3].

Hydrodynamic cavitation is observed in pipelines, in water monitors, and in flows encircling blades of centrifugal pumps, hydraulic turbines, and ship propellers. Cavitation leads to vibration, banging, and shaking, which leads to loosening of fastening links, breaking of bolts, collapse of threads, frictional corrosion of joints, violations of seals and fatigue damages.

Preconditions for cavitation wear are as follows. When vapor-gas bubbles are closed until complete disappearance near surface of a part, the latter is exposed to microscopic hydraulic shocks (Figure 3).
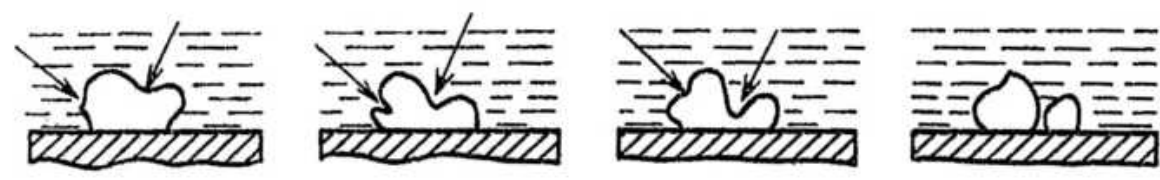

Figure 3: Schematic view of hydraulic shocks upon contraction of cavitation bubble

Among several millions of formed cavitation bubbles, approximately one bubble of 30 thousands participates in destruction. Under the impact of shocks, the metal surface is deformed and hardened; shearing lines are formed and some kind of etching takes place with revealing of boundaries of single grains. Multiple shocks lead to weakening and rehardening in certain microsites accompanied by formation of destruction centers in the form of cracks. Less strong structural constituent is destroyed first of all (ferrite in steels, graphite inclusions in cast iron). Then less strong constituents can be crumbled. Destruction takes place in grains or along their boundaries depending on strength of grains and bonds between them [4]. 
Cavitation can be prevented at design stage of hydromechanical system, so that pressure in all points of flow would not be lower than the point of vapor generation. However, a chance of cavitation occurrence should be always taken into account.

Intensity of cavitation wear depends on temperature, properties of liquid and material of parts. The influence of viscosity is insignificant. Wear is more intensive with the increase in surface tension. Addition of substances forming and promoting formation of emulsions in water (oils and emulsifiers) decreases surface tension of liquids and reduces cavitation wear. The highest intensity of wear under the action of cavitation and corrosion is observed in water at $50^{\circ} \mathrm{C}[5]$.

Cavitation resistance of material is determined by its composition and structure. The strength of carbon steel increases with the carbon content. However, when the carbon content reaches $0.8 \%$ and higher, the strength drops. Lamellar perlite is more stable than granular material. Addition of nickel and chromium to steel increases its strength due to lower ferrite content, increase in dispersity rate, etc. Globular shape of graphite is favorable. The most resistant is low alloyed cast iron $(1 \% \mathrm{Ni}, 0.3 \mathrm{Mo})$ with globular graphite, it should be used for casings of centrifugal pumps, gates and other units of heat and water supply systems [6].

Therefore, the region of cavitation destruction is quite often removed from the area of bubble generation. At first, material is progressively loosened leading to occurrence of numerous microcracks, then fine particles are crumbled. Under certain conditions, the cavitation erosion can exceed the rate of corrosion destruction in the same medium by thousands and hundreds of thousands of times. Destruction of parts under cavitation impact of liquid corrosion media significantly depends on composition and structure of alloy as well as liquid flow rate.

The main actions aimed at reconditioning of worn equipment, elimination of occurring faults are comprised either of its replacement, which is expensive and sometimes is impossible due to unavailability of required equipment, or of reconditioning using energy consuming processes, such as welding, surfacing, spraying (Figure 4).

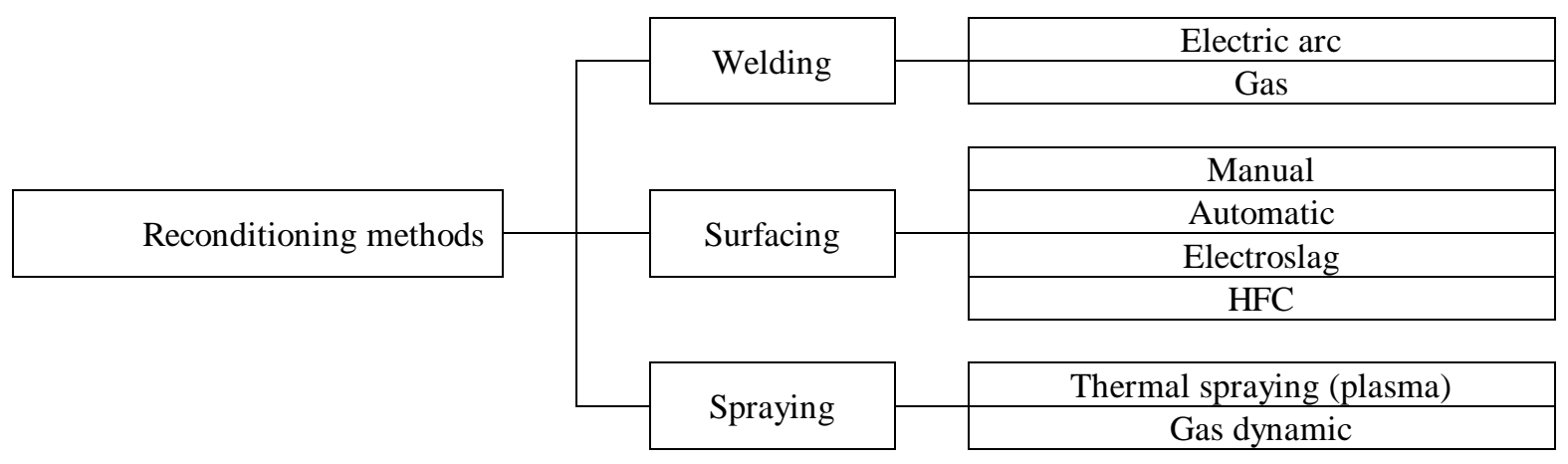

Figure 4: Classification of reconditioning methods of worn surfaces.

While welding eliminates cracks, cavities, ruptures, the high temperature heating in faulty sites leads to modification of structure and crystalline lattice in the vicinity of welding area. Herewith, plasticity in near-joint area decreases, the material becomes brittle, which subsequently can result in destruction.

Development of production service of various industries is based on application of new materials and application of advanced technologies, including application of coatings [7].

Protective coatings make it possible not only to obtain new properties of items due to the formed compositions combining high-operation lifetime (wear resistance, special properties) with sufficient reliability, but also to improve operation resistance of machine parts and tools, to restore worn surfaces and, hence, to decrease demands for spare parts. By means of the coating, peculiar properties of working surfaces are achieved due to optimization of properties of working item. Surface modification provides significant economy of deficient and expensive alloying metals used for bulk alloying in conventional production of alloys with special properties. The role of coatings should be mentioned with regard to development of surface compositions aiming at increase in structural strength in the case of strongly different properties of main metal and surface.

Optimization of application of protective corrosion and wear resistant coatings should be based on improvement of existing and development of new estimation procedures of structural strength of materials with coatings [8].

\section{METHODS}

Research methods of coating properties were considered with accounting for response illustrated below in Figure 5. 


\begin{tabular}{|c|}
\hline Research methods \\
\hline • \\
\hline Selection of materials and coating methods \\
\hline Analysis of structure \\
\hline$\cdot$ \\
\hline Analysis of properties \\
\hline$\cdot \cdot$ \\
\hline Improvement of technology \\
\hline Coating application \\
\hline
\end{tabular}

Figure 5: Flowchart of research methods of coating properties.

Analysis of coating structure should be supplemented and confirmed by data on mechanical, physical, and other properties. In its turn, this would allow to upgrade the technology and to discover new opportunities for its application [9].

Methods of coating application are numerous and various. However, at present, taking into account trends of technological development and demands of repair crews, the most promising are:

- application of composite coatings;

- plasma coating method;

- gas dynamic coating method.

Disadvantages of the second and the third methods were mentioned previously, whereas application of composite coatings during reconditioning of equipment is very simple and economically efficient. Analysis of this method is an urgent problem [10].

The aforementioned surfacing and spraying used for coating application on reconditioned surfaces are based on hightemperature two-phase flows, which leads to melting of the sprayed powders and their interaction with gas medium with generation of various compounds (oxides, nitrides, etc.) causing sometimes undesired variation of initial properties of powders and final coating. Another significant disadvantage involves substantial heating of parts and their deformation due to high residual stresses, insufficient strength of cohesion between particles and substrate, high porosity of coating, application of explosive gases, complicated maintenance and high cost of equipment, etc. [11].

New capabilities in the field of reconditioning of various equipment are achieved due to application of repair composite materials characterized by good adhesive strength and wear resistance, which can replace expensive and energy consuming technologies. Nowadays, due to their properties these materials are applied more and more frequently for production processes and reconditioning [12]. Composite materials characterized by wear resistant properties can be applied for reconditioning and preventive activities in mining industry, mechanical engineering, car and ship repairing, power engineering, chemical and oil processing industry, and some others.

Using the repair composite materials, it is possible to perform the following activities: application of wear resistant coatings, repair and protection of case structures against environmental impacts; shape restoration of eroded and corroded parts; coverage and sealing of cracks, indentions, holes, and others [2].

Reconditioning technologies are always necessary for equipment and life support systems not requiring for significant investments, material and labor resources [13]. Such requirements are met by repair polymer composite materials, their application is not based on expensive equipment, this is an adequate replacement for welding, soldering, surfacing. Rational use of physicochemical properties of polymer composite materials makes it possible to reduce significantly labor consumption and prime costs of reconditioning, as well as to decrease consumption of materials for such procedures.

The number of manufacturers of metal polymer compositions continuously increases both in Russia and abroad. And if in Russia the quality of these materials is not consistent due to poor initial constituents, then foreign manufacturers provide high-quality products with steady physical and engineering properties [14].

At present the composite materials of the following companies are available in Russian market: Durmetall, Diamant, Loctite, Belzona, Unirep, Devcon, Chester Molecular, and some others [3].

Among foreign companies producing metal polymer compositions and anaerobic adhesives, the most preferred is Chester Molecular (Poland), which supplies numerous materials of this kind. Materials of this company are characterized by consistent quality, their physical and engineering properties are at least the same as those supplied by Belzona (USA), Durmetall (Switzerland), Diamant (Germany), Loctite (USA), and some others, though they are less expensive, that is, on the basis of quality/price ratio, they are the most attractive. Chester Molecular company proposes a set of metal polymers of various properties and possibilities, including materials of universal application, fast curing, antifriction materials, materials for protection against corrosion and cavitation, specialized composite coatings, anaerobic adhesives and sealants, as well as various auxiliary liquids and equipment required for reconditioning using composite materials.

Reconditioning and application of protective coatings on working surfaces were performed according to the following flowchart (Figure 6): 
Vyacheslav Aleksandrovich Ivanov, International Journal of Emerging Trends in Engineering Research, 8(6), June 2020, 2635 - 2642

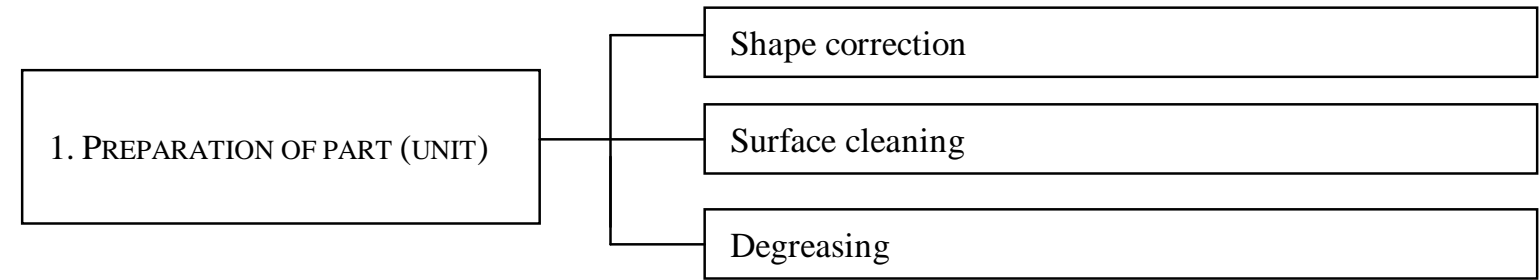

\begin{tabular}{|c|c|}
\hline & Manual \\
\hline \multirow{2}{*}{$\begin{array}{l}\text { 2. PREPARATION OF COMPOSITE } \\
\text { MATERIAL }\end{array}$} & Mechanized \\
\hline & \\
\hline
\end{tabular}

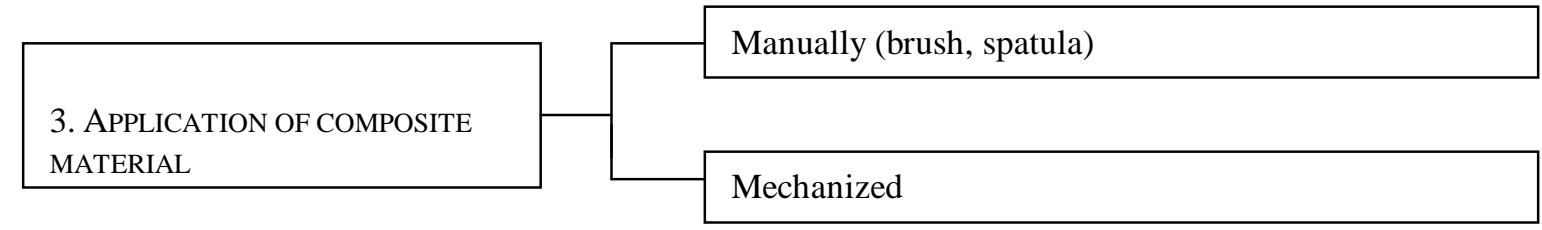

\begin{tabular}{|l|l|l|}
\hline \multirow{2}{*}{$\begin{array}{l}\text { 4. FORMATION OF COMPOSITE } \\
\text { LAYER }\end{array}$} & W/o pressure \\
\cline { 2 - 3 } & Fixed holders \\
\hline & Moving holders \\
\hline
\end{tabular}
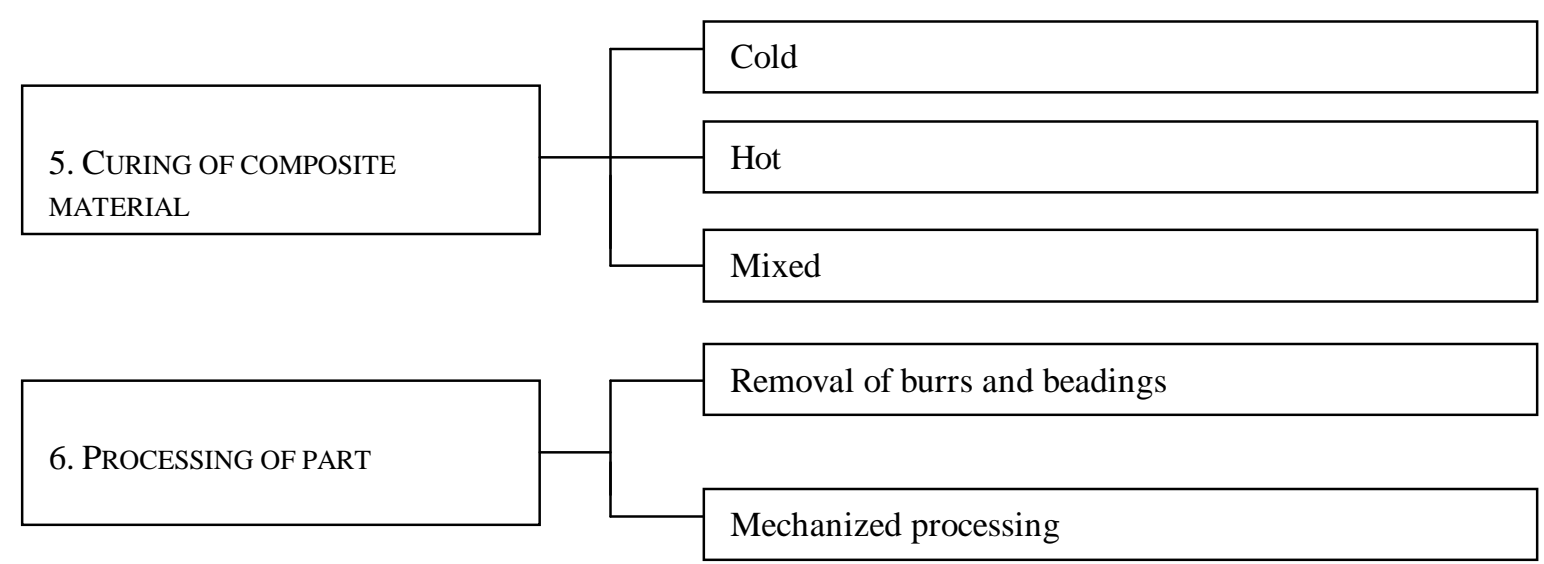

Figure 6: Flowchart of reconditioning process and retrofitting of parts using composite materials

\section{RESULTS}

On the basis of analysis of properties of repair composite materials by various manufacturers, it can be concluded that in order to repair the wear of metal surfaces in parts and units of life support systems, the most preferable materials are composites with ceramic fillers [15], which can be exemplified by composite materials by Chester Molecular company (Poland):

- Metal Ceramic T: pasty consistency;

- Metal Ceramic F, FHT, FSL: these three materials are liquids.

The main physicomechanical properties of these materials are summarized in Table 1. 
Vyacheslav Aleksandrovich Ivanov, International Journal of Emerging Trends in Engineering Research, 8(6), June 2020, 2635 - 2642

Table 1: Physicomechanical properties of Metal Ceramic materials

\begin{tabular}{|c|c|c|c|c|}
\hline Groups & \multicolumn{4}{|c|}{ Metal Ceramic } \\
\hline Description & Ceramic $\mathrm{T}$ & Ceramic F & Ceramic FHT & Ceramic FSL \\
\hline Consistency & Paste & \multicolumn{3}{|l|}{ Liquid } \\
\hline Specific weight, $\left(\mathrm{g} / \mathrm{cm}^{3}\right)$ at $25^{\circ} \mathrm{C}$ & 2.03 & 1.90 & 2.00 & 2.00 \\
\hline Color & grey & grey, blue & grey & grey, blue \\
\hline $\begin{array}{l}\text { Mixing ratio (base : activator) } \\
\text { - by weight } \\
\text { - by volume }\end{array}$ & $\begin{array}{l}2.5: 1 \\
2: 1\end{array}$ & $\begin{array}{l}9: 1 \\
\text { pack }\end{array}$ & $\begin{array}{l}9: 1 \\
\text { pack }\end{array}$ & $\begin{array}{l}9: 1 \\
\text { pack }\end{array}$ \\
\hline Viability of prepared composition at $20^{\circ} \mathrm{C}$, min & 20 & 15 & 20 & 50 \\
\hline $\begin{array}{l}\text { Curing time before possibility of mechanical } \\
\text { processing, } h\end{array}$ & 3.5 & 3.5 & 4 & 7 \\
\hline Maximum temperature stability, ${ }^{\circ} \mathrm{C}$ & 200 & 200 & 220 & 200 \\
\hline Working temperature, ${ }^{\circ} \mathrm{C}$ & $\begin{array}{ll}-50 \\
+150\end{array}$ & $\begin{array}{l}-50 \\
+150 \\
\end{array}$ & $\begin{array}{ll}-50 \\
+180 \\
\end{array}$ & $\begin{array}{ll}-50 \\
+150\end{array}$ \\
\hline $\begin{array}{l}\text { Ultimate strength, MPa } \\
\text { compressive (according to ICO 604) } \\
\text { bending (according to ICO 178) } \\
\text { shearing (according to ICO 4587) }\end{array}$ & $\begin{array}{l}144 \\
90 \\
22.8\end{array}$ & $\begin{array}{l}120 \\
110 \\
22.9\end{array}$ & $\begin{array}{l}120 \\
105 \\
15.4\end{array}$ & $\begin{array}{l}120 \\
110 \\
24\end{array}$ \\
\hline Storage time, months & 36 & & & \\
\hline Pack, kg & $\begin{array}{l}1 \\
2 \\
5\end{array}$ & $\begin{array}{l}0.5 \\
1 \\
3 \\
\end{array}$ & $\begin{array}{l}0.5 \\
1 \\
\end{array}$ & $\begin{array}{l}0.5 \\
1 \\
3 \\
\end{array}$ \\
\hline
\end{tabular}

Examples of application of Chester Metal Ceramic materials:

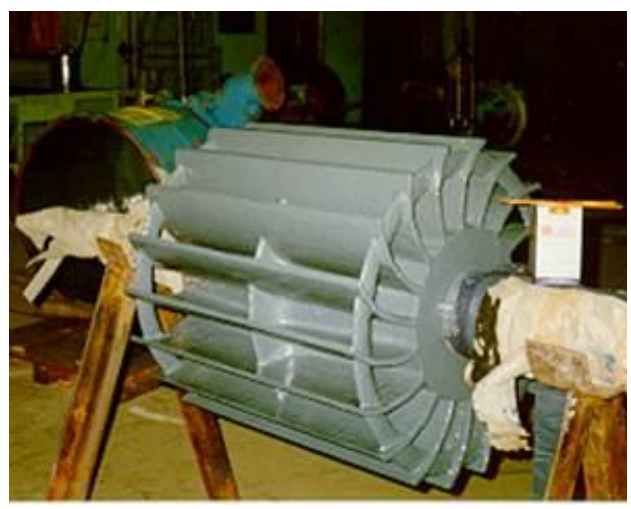

Figure 7: Reconditioning of pump volute

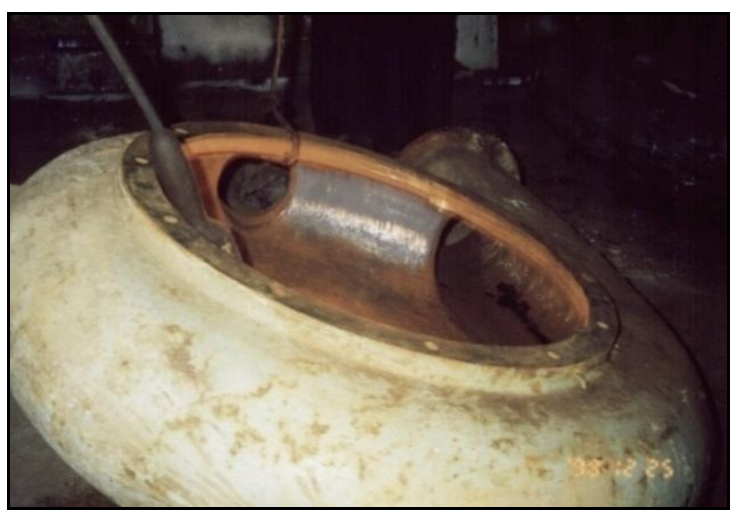

Figure 8: Reconditioning of rotor

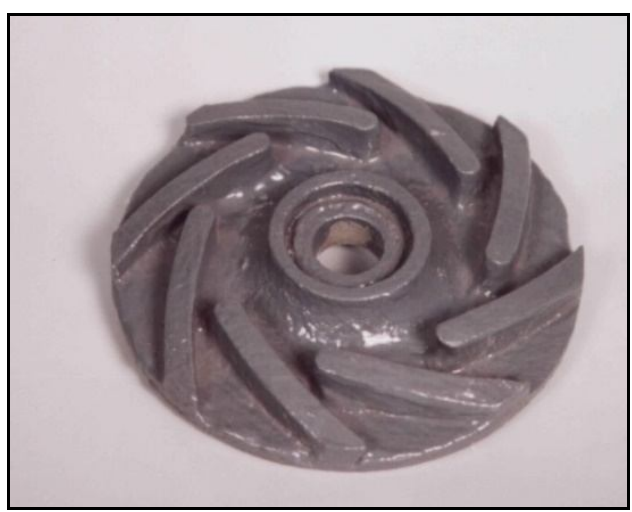

Figure 9: Reconditioning of pump impeller

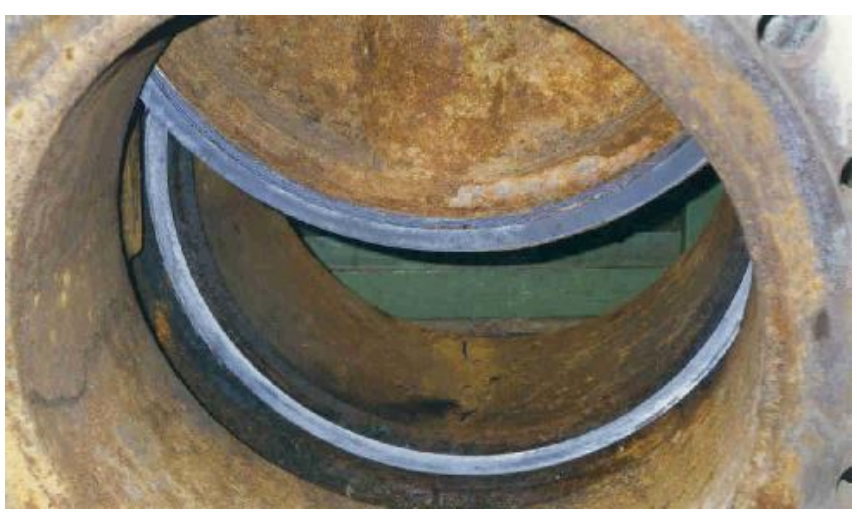

Figure 10: Reconditioning of wedge gate 


\section{DISCUSSION}

While analyzing Table 1, it should be mentioned that Metal Ceramic materials are characterized by superior mechanical properties. In addition, they are resistant against water, oils, motor fuels, nonconcentrated acid and alkalis, they obtain chemical resistance in seven days.

The Chester Ceramic materials are applied for reconditioning of ship propellers, rotor blades, corroded surfaces, pump housings, heat exchangers, wedge gates and other equipment.

\section{CONCLUSION}

At present, reconditioning composite materials are successfully applied for reconditioning of equipment and units in various industries, including car manufacturing, ship building, pulp and paper industry, engineering, as well as in housing and utilities sector upon operation of water supply, heat supply, and gas supply. Rational use of physicochemical properties of reconditioning composite materials allows reducing labor consumptions for reconditioning by $20 \%$, cost of works by $15-20 \%$, metal consumption by $40-50 \%$ [8]. This can be attributed to the fact that such technology does not require for complicated equipment and qualified personnel, allows to perform reconditioning without disassembling as well as making connections, reconditioning of which using conventional methods is difficult and dangerous in terms of safety.

The presented information demonstrates great opportunities of application of repair composites that allow providing rapid elimination of faults and subsequent reliable operation of process equipment and heat supply systems of housing and utilities sector.

Therefore, as evidenced by experimental results and available publications, application of repair composite materials, including those with ceramic fillers, increases operation lifetime of equipment and pipelines exposed to abrasive, corrosive, and cavitation wear. Herewith, prime cost of reconditioning is by 3-10 times lower in comparison with conventional procedures using welding, surfacing, spraying.

\section{REFERENCES}

1. A.B. Tulinov, V.A. Ivanov. Vosstanovlenie defektov blokov tsilindrov dvigatelei vnutrennego sgoraniya $\mathrm{s}$ ispol'zovaniem remontnykh kompozitsionnykh materialov [Reconditioning of cylinder block of ICE using repair composite materials]. Promyshlennyi servis, vol. 3, no. 68, pp. 27-30, 2018.

2. A. Ermakov, O. Mukhamedzhanova, Y. Tumenev. To the matter of the educated development of the construction industry of recreational territories. MATEC Web of Conferences, no. 106, article № 01042, 2017.

https://doi.org/10.1051/matecconf/201710601042
3. Yu.F. Nabatnikov, A.B. Goncharov, A.B. Tulinov, V.A. Ivanov. Advanced processes for reconditioning of cone crusher. Gornyi Zhurnal, no. 6, pp. 68-72, 2017. https://doi.org/10.17580/gzh.2017.06.13

4. V.A. Ivanov, A.B. Tulinov. Progressivnye metody remonta s ispol'zovaniem iznosostoikikh polimernykh kompozitsionnykh materialov [Advanced reconditioning methods using wear resistant polymer composite materials]. Conference Proceedings: Key Trends in Composite Materials, pp. 292-303, 2019.

5. A. Demenev, A. Naberezhnykh. Research of the process of formation of noise in Household Refrigerators. Akustika, no. 32, pp. 135-137, 2019.

6. A.V. Demenev, R.N. Lopatko, V.G. Zharov. Operation of Buildings and Structures Based on BIM Standards in the Digital Economy. International Multi-Conference on Industrial Engineering and Modern Technologies, FarEastCon, 2019, article № 8934034

7. V. Igonin, N.G. Bondarenko, O.N. Borisova, E.S.-M. Akhyadov, S.V. Garnik, P.Y. Meschkov. Medical equipment cost assessment in the conditions of intensive technological changes. International Journal of Engineering and Advanced Technology, vol. 9, no. 1, pp. 5004-5009, 2019.

https://doi.org/10.35940/ijeat.A2129.109119

8. V.A. Ivanov, A.B. Tulinov. Advanced repair methods using wear-resistant polymeric composite materials. IOP Conference Series: Materials Science and Engineering, vol. 683, conference 1. https://doi.org/10.1088/1757-899X/683/1/012031

9. A.B. Tulinov, V.A. Ivanov. Rezul'taty issledovaniya fiziko-mekhanicheskikh svoistv anaerobnykh materialov [Studying physicomechanical properties of anaerobic materials]. Promyshlennyi servis, vol. 1, no. 66, pp. 13-18, 2018.

10. V.A. Suchilin, L.V. Sumzina, A.V. Maksimov. Method for Refrigerators Efficiency Increasing. IOP Conference Series: Materials Science and Engineering, 262(1), article № 012121, 2017. https://doi.org/10.1088/1757-899X/262/1/012121

11. V.V. Lebedev, L.V. Sumzina, A.V. Maksimov. Method for Household Refrigerators Efficiency Increasing. IOP Conference Series: Materials Science and Engineering, 262(1), article № 012122, 2017. https://doi.org/10.1088/1757-899X/262/1/012122

12. A.A. Ishchenko. Novye polimernye materialy v praktike remonta promyshlennogo oborudovaniya [New polymer materials in practical reconditioning of industrial equipment]. Vestnik dvigatel'stroeniya, no. 3, pp. 130132, 2004.

13. S.V. Shaytura, A.M. Minitaeva, K.V. Ordov, V.V. Shaparenko. Virtual enterprises in a spatial economy. International Journal of Recent Technology and Engineering, vol. 7, no. 6, pp. 719-724, 2019.

14. S.V. Shaytura, M.D. Knyazeva, V.M. Feoktistova, T.A. Vintova, V.A. Titov, Y.P. Kozhaev. Philosophy of information fields. International Journal of Civil 
Vyacheslav Aleksandrovich Ivanov, International Journal of Emerging Trends in Engineering Research, 8(6), June 2020, 2635 - 2642

Engineering and Technology, vol. 9, no. 13, pp. 127136, 2018.

15. E.V. Pavlova, A.A. Silayeva, O.N. Borisova, I.G. Doronkina, A.P. Sokolova. Analysis of the world and Russian E-commerce market: Development trends and challenges. International Journal of Engineering and Technology, vol. 7, no. 4, pp. 387-392, 2018. https://doi.org/10.14419/ijet.v7i4.38.24588 